The Argonne Boundary Layer Experiments Facility: Using Minisodars to Complement a Wind Profiler Network

R. L. Coulter, G. Klazura, B. M. Lesht, J. D. Shannon, D. L. Sisterson, M. L. Wesely

Argonne National Laboratory Argonne, IL 60439

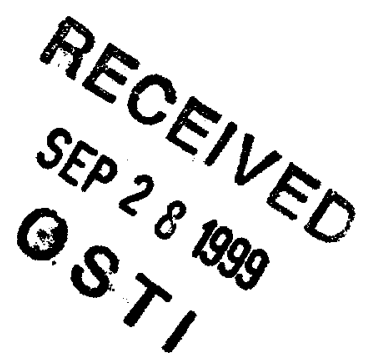

The submitted manuscript has been created by the University of Chicago as Operator of Argonne National Laboratory ("Argonne") under Contract No. W-31-109-ENG-38 with the U.S. Department of Energy. The U.S. Government retains for itself, and others acting on its behalf, a paid-up. nonexclusive, irrevocable worldwide license in said article to reproduce, prepare derivative works, distribute copies to the public, and perform publicly and display publicly, by or on behalf of the Government. 


\section{DISCLAIMER}

This report was prepared as an account of work sponsored by an agency of the United States Government. Neither the United States Government nor any agency thereof, nor any of their employees, make any warranty, express or implied, or assumes any legal liability or responsibility for the accuracy, completeness, or usefulness of any information, apparatus, product, or process disclosed, or represents that its use would not infringe privately owned rights. Reference herein to any specific commercial product, process, or service by trade name, trademark, manufacturer, or otherwise does not necessarily constitute or imply its endorsement, recommendation, or favoring by the United States Government or any agency thereof. The views and opinions of authors expressed herein do not necessarily state or reflect those of the United States Government or any agency thereof. 


\section{DISCLAIMER}

Portions of this document may be illegible in electronic image products. Images are produced from the best available original document. 


\title{
The Argonne Boundary Layer Experiments Facility: Using Minisodars to Complement a Wind Profiler Network
}

\author{
R. L. Coulter, G. Klazura, B. M. Lesht, J. D. Shannon, \\ D. L. Sisterson, M. L. Wesely \\ Argonne National Laboratory \\ Argonne, IL 60439
}

\section{Introduction}

The Argonne Boundary Layer Experiments (ABLE) facility, located in south central Kansas, east of Wichita, is devoted primarily to investigations of and within the planetary boundary layer (PBL), including the dynamics of the mixed layer during both day and night; effects of varying land use and land form; the interactive role of precipitation, runoff, and soil moisture; storm development; and energy budgets on scales of 10 to $100 \mathrm{~km}$. Located entirely within the Walnut River watershed, ABLE provides intense measurements within the northeast quadrant (Fig. 1) of the Southern Great Plains (SGP) Cloud

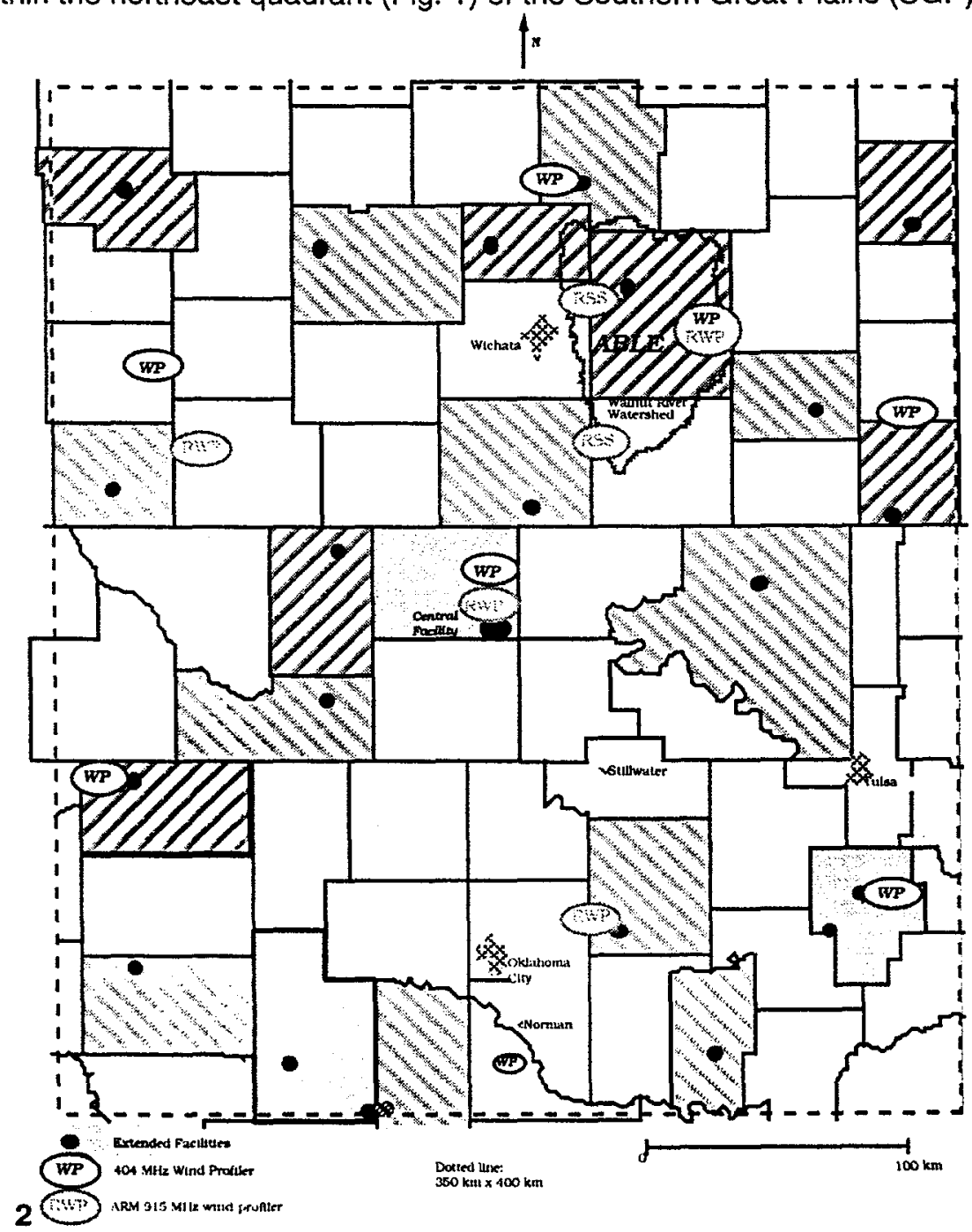

Figure 1. The ARM SGP CART site in northern Oklahoma and southern Kansas, USA. The ABLE facility is located in outlined area in the northeastern portion. Extended facilities contain surface flux measurement systems. 
and Radiation Testbed (CART) of the Atmospheric Radiation Measurement (ARM) Program (Stokes and Schwarz, 1994). By combining the continuous measurements of ABLE with ancillary continuous measurements of, for example, the ARM and the Global Energy Water cycle Experiment (GEWEX) (Kinster and Shukla, 1990) programs, ABLE provides a platform within which shorter, more intensive studies, such as those conducted by the Cooperative Atmosphere-Surface Exchange Studies (CASES) Program, can realize the full benefit of a wide variety of atmospheric measurements on many scales; this allows the study of hypothesized features of PBL development and dynamics, including frontal dynamics, nocturnal boundary development and breakdown, urban heat island effects, precipitation enhancement, and modification of the surface energy budget partitioning.

\section{Site description}

The ABLE site (Fig. 2), located in Butler, Sedgewick, and Cowley Counties, covers an area approximately $80 \mathrm{~km} \times 80 \mathrm{~km}$, encompassing the lower half of the Walnut River watershed. The western edge of ABLE lies less than $10 \mathrm{~km}$ east of the eastern city limits of Wichita and includes the fringes of the Wichita urban area. The present configuration includes three remote sensing sites (RSSes) located at the boundaries of the study area, a single surface flux site (SFS) located in the southeastern portion of ABLE above grassland, and a central site (CS), all of which have come into operation since July 1996. At least one additional SFS will be installed in 1998 above cropland, with an eventual total of five planned above various surface types.

Each RSS combines a radar wind profiler (RWP) with radio acoustic sounding system (RASS) and a minisodar (MS) (Coulter and Martin, 1986) to provide complete wind profiles from $10 \mathrm{~m}$ to $4 \mathrm{~km}$ or more and virtual temperature profiles from 100 to $2500 \mathrm{~m}$ above the surface. Also included at each RSS is an automatic weather station (AWS) consisting of a $10-\mathrm{m}$ tower instrumented to measure winds, temperatures, vapor pressure, and precipitation. Finally, each RSS also yields soil moisture estimates made with a time-domain refractometry method. Instrumentation at the RSSes and SFSes is summarized in Table 1. Locations of the sites are shown in Table 2. The site near Beaumont, Kansas (RSS2), is shared between the ARM program and ABLE. Except for the ARM central site at Lamont Oklahoma, the ARM RWP sites include no ancillary measurements. Thus, ABLE augmented the
Beaumont site with the MS, AWS and soil moisture sensors; the data from the

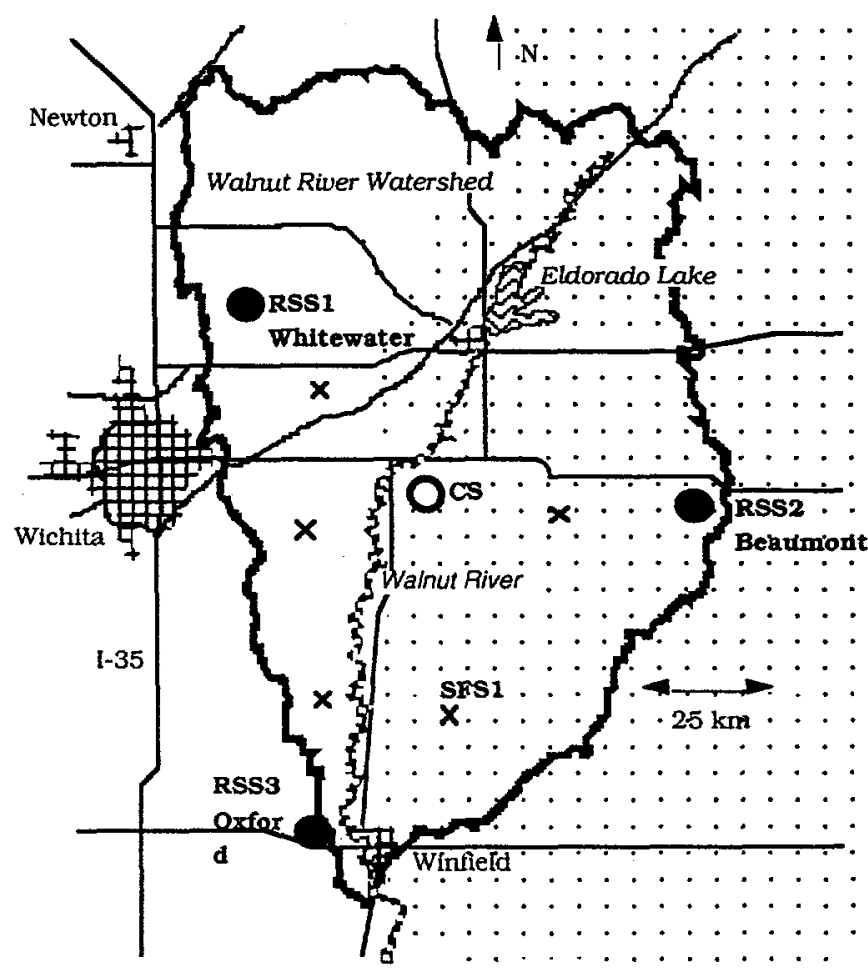

Cs: central site

RSS: remote sensing site

SFS: surface flux site

Figure 2. Map of the ABLE facility. Hatched area to the east denotes rangeland or grassland. The remaining area is primarily cropland. The $X^{\prime} s$ without labels are surface fiux sites that have not yet been installed.

RWP at Beaumont are incorporated into the ABLE data stream directly, rather than by access to the ARM data archive, which would entail significant delay.

The SFS consists of an AWS and eddy correlation (EC) instrumentation to measure the fluxes of temperature (sensible heat, $H$ ), moisture (latent heat, $L E)$, momentum $\left(u^{*}\right)$, and carbon dioxide $\left(\mathrm{FCO}_{2}\right)$.

The EC instruments are mounted above a 2 mtall mast (rather than on its side) to allow for flux measurements from 
Table 1. ABLE instruments, sites, heights, and parameters measured.

\begin{tabular}{|c|c|c|c|}
\hline System & Sites & $\begin{array}{c}\text { Measurement } \\
\text { heights }(\mathrm{m})\end{array}$ & $\begin{array}{l}\text { Parameters } \\
\text { measured }\end{array}$ \\
\hline RWP & $\begin{array}{c}\text { RSS } \\
1,2,3\end{array}$ & $\begin{array}{l}100-4000 \\
\text { every } 60\end{array}$ & $s, d, s n r, T_{v}$ \\
\hline $\begin{array}{c}M S \\
\text { AWS }\end{array}$ & $\begin{array}{c}\text { RSS } \\
1,2,3 \\
\text { RSS }\end{array}$ & $\begin{array}{l}10-200 \\
\text { every } 5\end{array}$ & $s, d, s n r$ \\
\hline & $\begin{array}{c}1,2,3 \\
\text { SFS1, } \\
\text { CS }\end{array}$ & 10 & $s, d, e, P$ \\
\hline$E C^{b}$ & SFS1 & 2.5 & $\begin{array}{c}\mathrm{H}, \mathrm{LE}, \mathrm{u}^{*}, \mathrm{~s}, \\
\mathrm{~d}, \mathrm{FCO}_{2}\end{array}$ \\
\hline
\end{tabular}

Table 2. Site locations and instruments

\begin{tabular}{|c|cccc|}
\hline Site & $\begin{array}{c}\text { Lat } \\
\text { (deg) }\end{array}$ & $\begin{array}{c}\text { Lon } \\
\text { (deg) }\end{array}$ & $\begin{array}{c}\text { Altitude } \\
(\mathrm{m})\end{array}$ & $\begin{array}{c}\text { Instrument } \\
\text { systems }\end{array}$ \\
\hline RSS1 & 37.85 & 97.18 & 420 & $\begin{array}{c}\text { RWP, MS, } \\
\text { AWS }\end{array}$ \\
RSS2 & 37.62 & 96.53 & 478 & $\begin{array}{c}\text { RWP, MS, } \\
\text { AWS }\end{array}$ \\
RSS3 & 37.27 & 97.09 & 360 & $\begin{array}{c}\text { RWP, MS, } \\
\text { AWS }\end{array}$ \\
SFS1 & 37.52 & 96.85 & 408 & $\begin{array}{c}\text { EC, AWS } \\
\text { AWS }\end{array}$ \\
\hline $\begin{array}{c}\text { CS } \\
\text { AW.62 }\end{array}$ & 96.88 & 400 & A \\
\hline
\end{tabular}

any wind direction; thus, the requirements for an adequate SFS are often quite difficult to fulfill, particularly over cropland. The first SFS is located over grassland, which predominates in the eastern half of the region; the next SFS will be placed above cropland to the west of the Walnut River.

A network of 45 rain gauges was installed by Oregon State University in the northwest quadrant of the ABLE area, in the Towanda subbasin, during the first intensive measurement period of CASES in AprilMay 997 , as part of a comparison study for the improvement of -radar estimation algorithmsfor rainfall. The rain gauge network will remain in place for long-term studies and is being augmented with a soil moisture measurement system that samples soil moisture profiles by using time-delay refractometers at 16 locations within a $100-\mathrm{m} \times 100-\mathrm{m}$ area.

Data from each of the sites (not including the rain gauge network) are collected by telephone data link every hour at the CS near Augusta, Kansas. The CS will also be the location of a rawindsonde system, a ceilometer, and an AWS, to be installed in the next year. The CS will also contain prepared locations (power, computer hookups, etc.) for additional instruments brought to the site by researchers, either for comparison with site measurements or to complement the array of instruments already present. In addition, limited office space for visiting scientists is available at the CS.

The data are immediately displayed for initial inspection at the CS, following which they are compressed and sent simultaneously to Argonne National Laboratory, where they are processed and placed on the Internet, available for public inspection and retrieval by interested users within 2 hours of the time of measurement. "Real-time" data displayed on the Internet connection to allow more rapid turnaround for field study procedures (aircraft vectoring, for example) are generally not quality controlled. The RWP and MS data are passed through quality control filters every 24 hours and placed in a data archive for retrieval by interested scientists.

\section{The role of the minisodar}

The MS is a critical element in the detailed measurements necessary for a complete description of the PBL. Although RWPs nominally begin data collection $100 \mathrm{~m}$ above the surface, this lowest range gate is very often contaminated with ground clutter and either is rejected by quality control procedures or remains of questionable value. The minisodar provides both verification data at the lower RWP range gates and a detailed wind profile below this level. Figure 3 shows an example of profiles from both the MS and the RWP. Note that the agreement is good above the lowest RWP gate; however, the lowest RWP value is

a Parameters measured and not defined in the text include wind speed (s), wind direction (d), virtual temperature $\left(T_{v}\right)$, vapor pressure $(e)$, pressure $(P)$, and signal-to-noise ratio (snr).

b Weather stations and eddy correlation stations will also be located at future flux sites.

obviously in error. The MS is particularly valuable during nighttime conditions when the stable boundary 
layer is only a few hundred meters deep and energy transfer often occurs on very short time scales, or overturning events. The fine scale (5-m range gates) of the MS amplitude and vertical velocity variance estimates is particularly useful in defining these events.
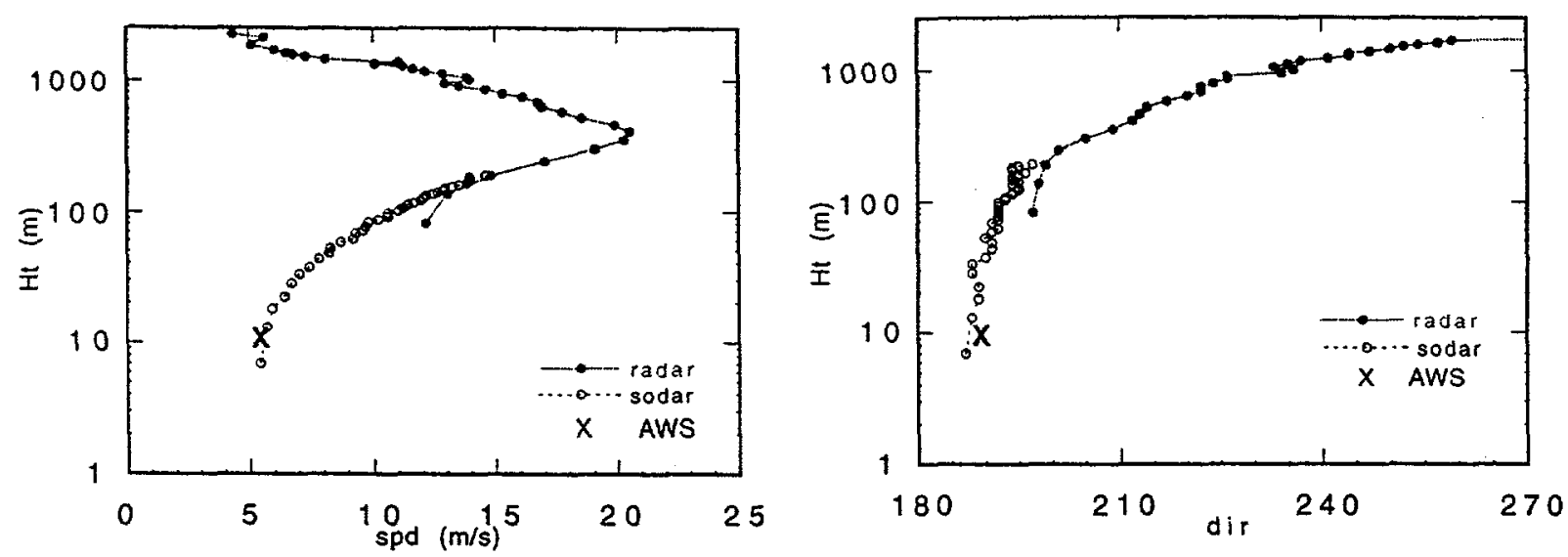

Figure 3. Profiles of MS and wind RWP data during low -level jet conditions on 18 Jun 1997. Note the problem with lowest-level profiler value that is made obvious by MS data.

One of the products soon to be regularly available from ABLE is an estimate of divergence over the depth of the mixed layer during daytime for the triangle of RWPs. By using the collocated minisodars as a second, independent, estimate of divergence, we can better apprais the reliability of the RWP estimate (Fig. 4).

\section{Additional products}

In addition to the basic measurements available directly through the World Wide Web access (http://www.atmos.anl/ABLE), derived products are being developed to be available on a regular basis . These include the following:

Mixed Layer Height. Both a subjective and an objective estimate to be derived from RWP signalto-noise ratio profiles.

Divergence. The area-wide vertical velocity at the top of the mixed layer, to be calculated by integrating the divergence calculated from radar and sodar triangles.

Model-Measurement Comparison. A regular comparison of mesoscale model estimates of temperature and wind profiles with measurements.

\section{Acknowledgement}

This work was supported by the U. S. Department of Energy, Office of Energy Research, Office of Biological and Environmental Research, Environmental Sciences Division, under contract W-31-109 Eng38.

\section{Refererences}

Coulter, R. L., and T. J. Martin, 1986: Results from a high power, high frequency sodar, Atmospheric Research $20(2-4), 257-270$.

Kinster, J. L., and J. Shukla, 1990: The global hydrologic and energy cycles: Suggestions for studies in the pre-Global Energy and Water Cycle Exchange (GEWEX) period. Bull. Am. Meteorol. Soc. 71, $181-189$.

Stokes, G. M., and S. E. Schwartz, 1994: The Atmospheric Radiation Measurements (ARM) Program: Programmatic background and design of the Cloud and Radiation Testbed. Bull. Amer. Meteorol. Soc. $75,1201-1221$. 